\title{
Numerical Simulation on Bifurcate Fracture of Linear Red Copper Penetrator
}

\author{
Shuhai Zhang and Ruijun Gou*
}

Department of Safety Engineering, North University of China Taiyuan, Shanxi, 030051, P. R. China

\begin{abstract}
The Red copper has been widely used in shaped charge liner because of good ductility. Red copper penetrator is a Linear Explosively Formed Penetrator (LEFP) when linear red copper shaped charge liner overturned under the effect of detonation production. Compared with ordinary jet swords, red copper penetrator has a wider range of stand-off, bigger cratering and significant aftereffect, which can meet the requirements in various environments. It was observed that bifurcate fracturing of red copper penetrator occurred in the performance testing of LEFP initiated on edge midpoint as the stand-off increased, which resulted in the separate craters on the target and the cratering effect was weakened. The Propagation of detonation wave and the interaction with red copper shaped charge liner were theoretically and experimentally studied, also numerical simulations were conducted. The results showed that velocities of charge liner elements were directly proportional to those of detonation waves, which caused different velocity directions and values of different elements, and great velocity gradient formed in the penetrator. The penetrator fractured as the elongations both on the vertical and horizontal directions were greater than the dynamic elongation of red copper. It was concluded that the main factor which resulted in the bifurcate fracture phenomenon was velocity gradient in the penetrator.
\end{abstract}

Keywords: Linear red copper penetrator, bifurcate fracture, stand-off, numerical simulation.

\section{INTRODUCTION}

A linear shaped charge (LSC) has a liner with wedgetype (or V-shaped) profile. The liner is surrounded with explosive. When explosive detonated, the liner collapsed under pressure and a plane jet sword formed. LSCs are commonly used in the cutting of rolled steel joists (RSJ) and other structural targets $[1,2]$. Because the performance of the linear shaped charge is determined by the jet which is restricted by the charge structure, there are serious limitations in stand-off and aftereffect for some special applications.
The linear metal charge case is overturned under the effect of detonation production after the explosive in the linear shaped charge was detonated [2], then a Linear Explosively Formed Penetrator (LEFP) is formed on the symmetrical surface of the charge with certain length along vertical direction. Compared with ordinary jet swords, LEFP has some characteristics such as a wide range of stand-off, big cratering and significant aftereffect and can meet lots of specific requirements in various environments.

The structure of LEFP charge is three-dimensional and complicated, and can be detonated in several ways such as

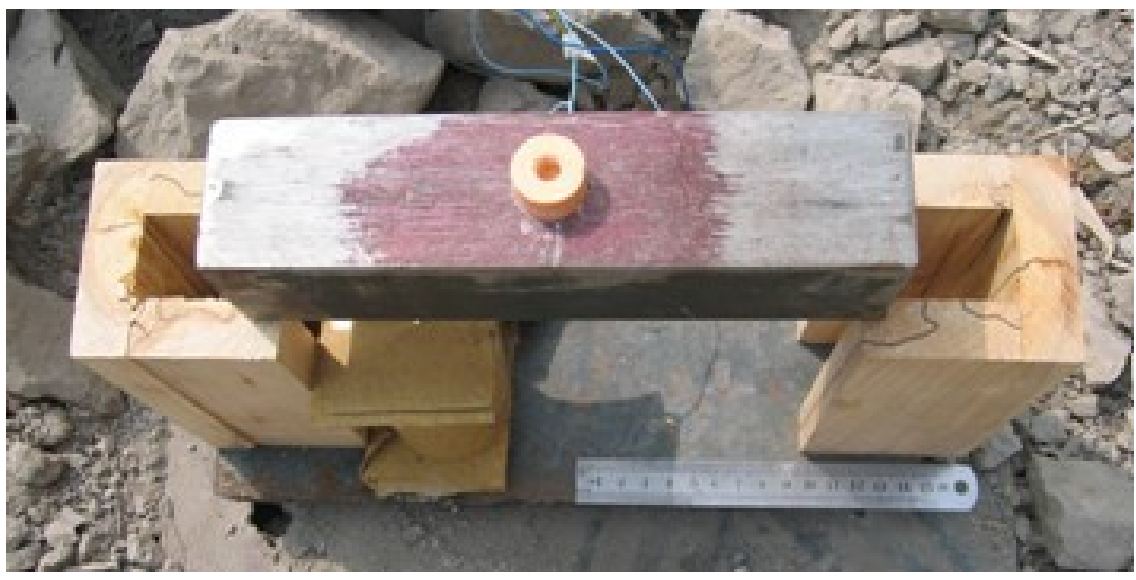

Fig. (1). Charge structure scheme and test setup.

*Address correspondence to this author at the School of Chemical Engineering and Environment, North University of China, Xueyuan Road 3, Taiyuan, Shanxi, 030051 China; Tel: +86-0351-3921446 (Office), +8613994272808; Fax: +86-0351-3922118; E-mail: grjzsh@163.com point detonation at end face, or edge, etc. LEFP charge simultaneously detonated on the edge is substantially same to EFP conical charge except that projectile shapes are different. But this simultaneous detonation is difficult to implement because of its high precision requirement. The 
end face point initiation and edge midpoint initiation are mainly applied for linear shaped charge.

Liner is the core part of shaped charge structure [3]. Metal materials with the better ductility were often chosen to forge the projectile, preferred red copper. Yet bifurcate fracturing of red copper penetrator was observed in the performance testing of LEFP initiated on edge midpoint as the stand-off increased. It results in the separate craters on the target and the cratering effect is weakened. In this paper, the bifurcate fracture model of LEFP is numerically simulated, and is discussed based on experiments and theoretical analysis.

\section{EXPERIMENT}

The charge structure is shown in Fig. (1). Shells of the shaped charges are made of $45 \#$ steel ( $2 \mathrm{~mm}$ thick). Explosives used are composition B and material of the liner is oxygen-free copper.
Target is made of $45 \#$ steel; booster charge is insensitive PETN. Detonator is $8 \#$ military detonator. Stand-off is controlled by U-shaped wood blocks.

Figs. (2, 3 and $\mathbf{4})$ showed the experiment results when the stand-off is 5,10 and 20 times of charge caliber respectively.

From experimental results, it can be seen that LEFP has been formed when the stand-off was 5 times of charge caliber. The separating crater phenomenon arose near detonation point when the stand-off was 10 times of charge caliber, and came to more evident when the stand-off was 20 times of charge caliber. This indicates that bifurcate fracture phenomenon occurs in the course of the LEFP movement.

\section{NUMERICAL SIMULATION}

A half model was set according to the symmetry, which represented to the left half charge from the detonation point. The model length is $100 \mathrm{~mm}$ from the detonation point. LS-

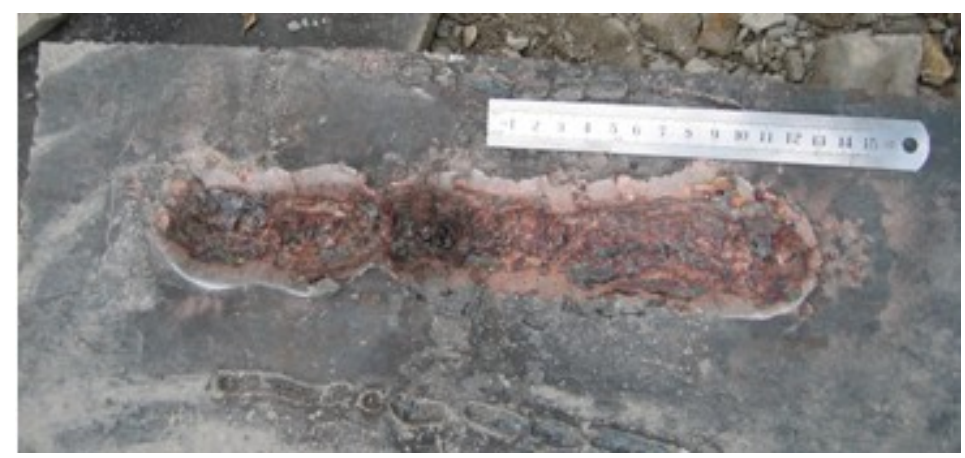

Fig. (2). Target result on the condition 5 times charge caliber stand-off.

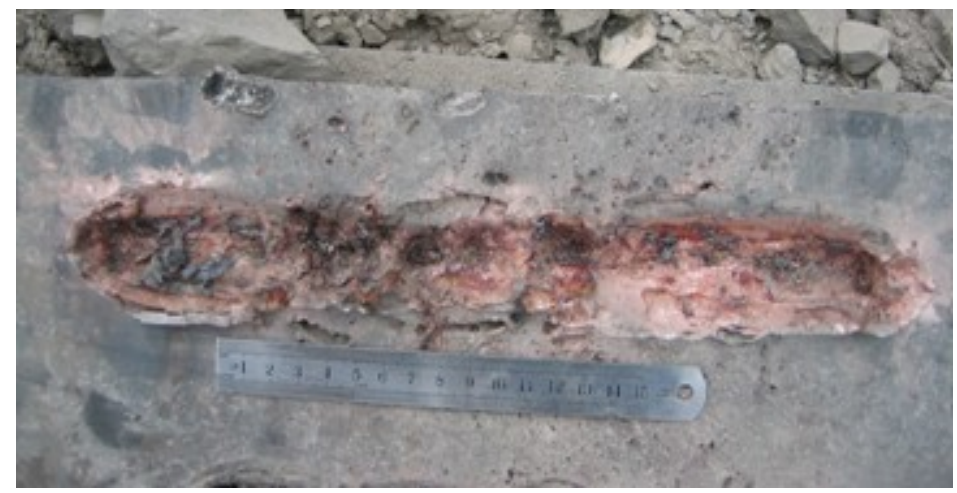

Fig. (3). Target result on the condition 10 times charge caliber stand-off.

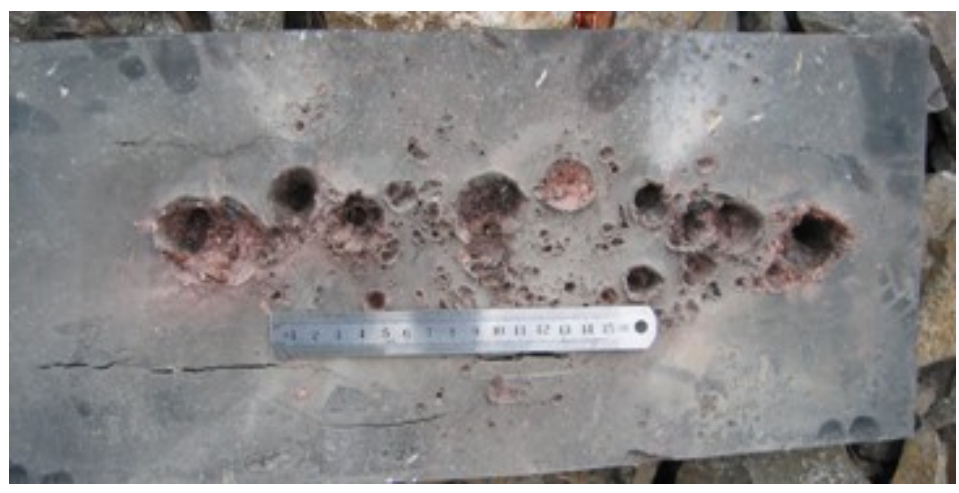

Fig. (4). Target result on the condition 20 times charge caliber stand-off. 
Dyna code was employed and total computing time was set to $240 \mu \mathrm{s}$. Fig. (5) showed the simulation of the penetrator shapes in time sequence.
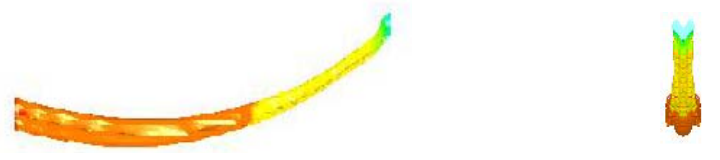

$104 \mu \mathrm{s}$ Front

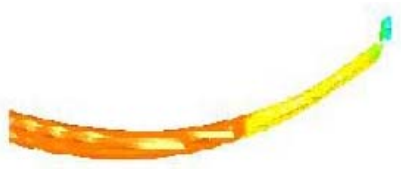

$106 \mu$ s Front

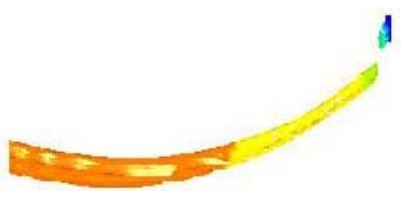

$112 \mu$ s Front

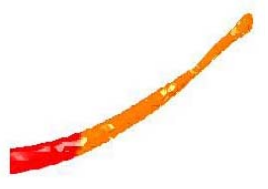

$214 \mu$ s Front

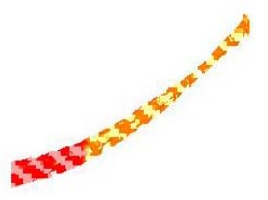

$228 \mu \mathrm{s}$ Front

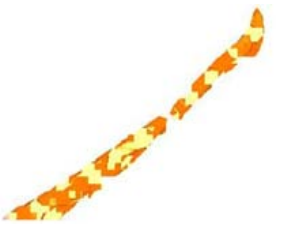

$238 \mu$ s Front
$104 \mu$ s Lateral

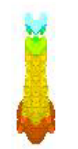

$106 \mu$ s Lateral

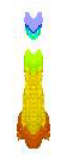

$112 \mu$ s Lateral

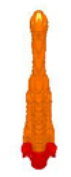

$214 \mu$ sateral

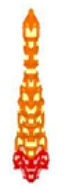

$228 \mu$ s Lateral

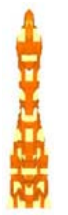

$238 \mu$ s Lateral
Fig. (5). The simulation of bifurcate fracturing of linear red copper penetrator.

It can be seen that in Fig. (5) a bifurcate fracture showed up near the detonation point at $104 \mu \mathrm{s}$, and completed at $112 \mu \mathrm{s}$. More fractures showed up at $228 \mu \mathrm{s}$, and the top one completed at $238 \mu \mathrm{s}$. Owing to the continuous bifurcate fracturing, the penetrator broke into several parts which resulted in the separate carters on the target.

Fig. (6) illustrated that the variations of $V_{y}$ (the vertical components of the velocity vectors of the penetrator tip) along the longitudinal direction, each curve for one moment. $V_{y}$ was increasing along the charge length as the distance from the detonation point increased. The changes of $V_{y}$ at different positions were different, as shown in the figure. On the part near the detonation point (between $0 \sim 22.5 \mathrm{~mm}$ ) it increased more quickly than that on the other part. The nearer to the detonation point, the greater change of $V_{y}$ was. The increase of $V_{y}$ was slowed down, and almost no increase at the point of $22.5 \mathrm{~mm}$. It decreased cross the point of $22.5 \mathrm{~mm}$. The decreases of $V_{y}$ at different points were similar in the range of $22.5 \sim 80 \mathrm{~mm}$, while the decreases changed to different at the points greater than $80 \mathrm{~mm}$ because of the effect of rarefaction wave from the other end. Consequently, the velocity gradient in LEFP were gradually decreasing after $80 \mathrm{~mm}$, as shown in the figure, the curves slowly approached to horizontal direction, and met to the same end. The reason is that as continuum medium there are mutual implications between different elements of the penetrator, which reduce the great velocity and enlarge the less one.

Fig. (7) illustrated that the variations of $V_{x}$ (the horizontal components of the velocity vectors of the penetrator tip) along the longitudinal direction. It can be seen that $V_{x}$ was also increasing along the charge length as the distance from the detonation point increased. The changes of $V_{x}$ were also different at different positions. The nearer to the detonation point, the greater change of $V_{x}$ was. The increase of $V_{x}$ was slowed down at the far end, and almost no increase between $60 \sim 70 \mathrm{~mm}$. On the other hand, the nearer to the other end, the value of $V_{x}$ decreased more quickly. Thus, there were significant gradients of $V_{x}$ in the parts near to two ends of the penetrator model, which result in that the penetrator stretched on horizontal direction. Under the combining stretch effect both horizontal and vertical, bifurcate fracture formed in the penetrator.

\section{RESULTS AND DISCUSSIONS}

\section{Mechanism of Bifurcate Fracture}

The primary cause of the bifurcate fracture was the velocity gradient in the penetrator, which made the penetrator close to detonation point bend, and simultaneously stretched the penetrator on two directions. The velocity gradient was caused by the detonation growth in the situations of which the charge was detonated at the midpoint of the edge or the point on end face.

\section{LEFP Bifurcate Fracture Model}

The generation mechanisms of bifurcate fracture were same for both situations of the edge midpoint and end face detonating. Here the mechanism was analyzed in the latter case.

The LEFP model as shown in Fig. (8), $\mathrm{R}$ axis is along the length direction of the charge, and the bottom of the liner is set to $\mathrm{S}=0$. The detonating face is set to $\mathrm{R}=0$.

The change of detonation wave velocity from detonation point is expressed as:

$$
\left(\frac{D}{D_{s}}\right)^{2}=1+\frac{2 \gamma^{2} L^{\alpha}}{(\gamma+1) \gamma^{\alpha} R^{\alpha}}
$$

The reversal velocity of the liner can be expressed as [4]: 


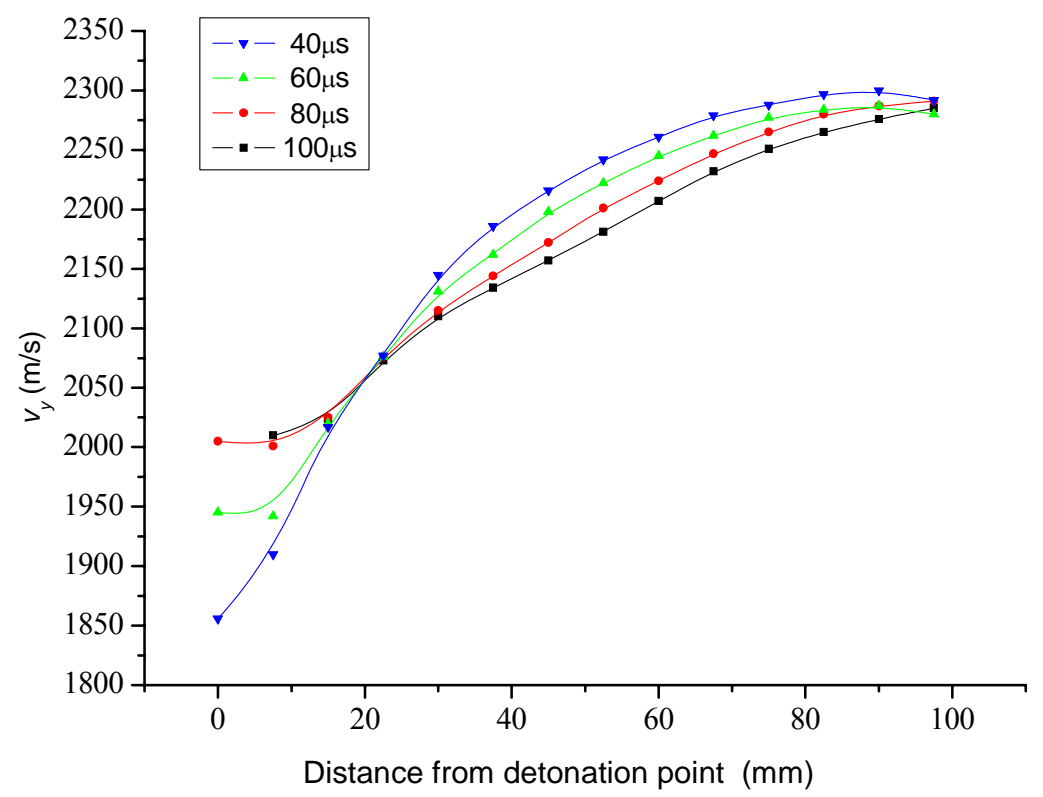

Fig. (6). Vertical velocity variation of the penetrator tip along the longitudinal direction.

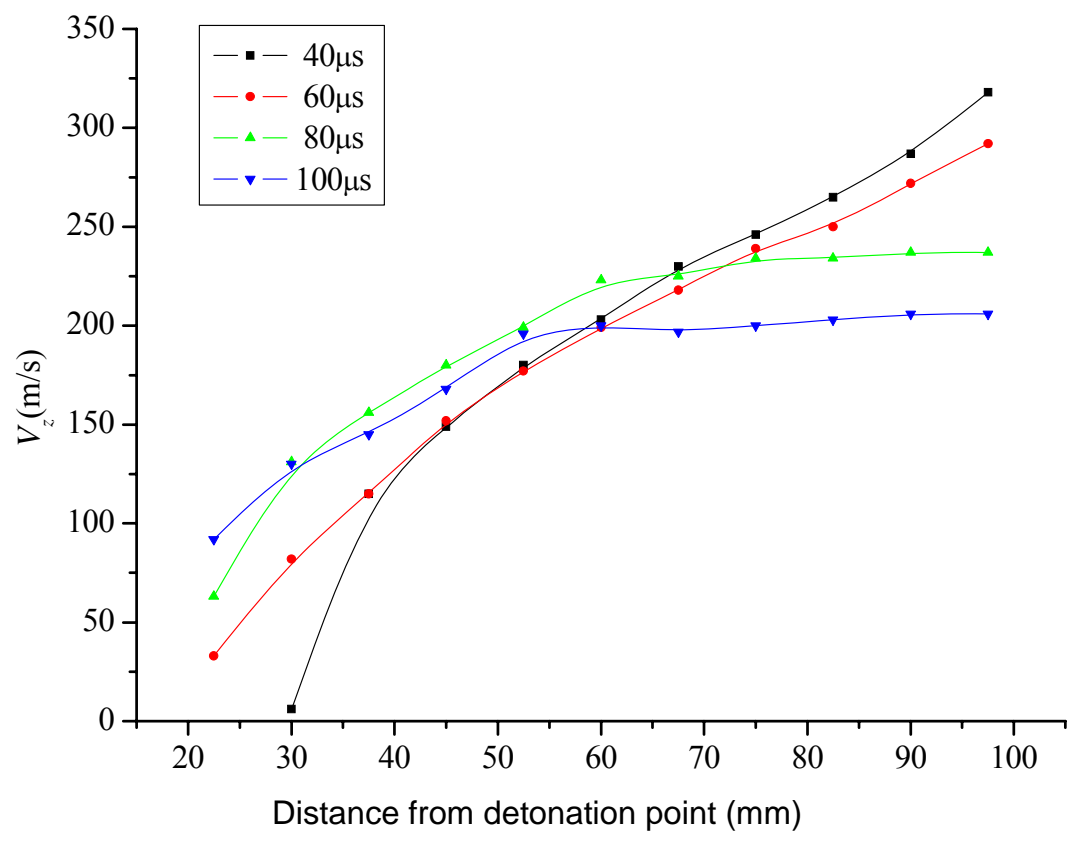

Fig. (7). Horizontal velocity variation of the penetrator tip along the longitudinal direction.

$$
V_{F}=\sqrt{2 E}\left\{\frac{1}{3}\left[\left(\frac{2 M}{C}\right)^{2}+\frac{5 M}{C}+1\right]\right\}^{-1 / 2}
$$

Where

$\sqrt{2 E}=$ Gurney constant of explosive, $\sqrt{2 E}=0.52+0.28 D_{S}$;

$\mathrm{D}=$ ideal of detonation velocity;

$\mathrm{M}=$ mass of liner element;

$\mathrm{C}=$ explosive mass corresponding to the liner element;

$\mathrm{r}=$ adiabatic index of detonation products;
$\mathrm{L}=$ width of reaction zone;

$\mathrm{R}=$ propagation radius of detonation wave.

It takes time $T$ that the detonation wave travels to the end of the charge, and the penetrator has been formed in this period. Assuming the elements reversal velocity of shaped charge liner is constant, and only considering the movements in $y$-direction, the distance that the liner element traveled till time $T$ :

$$
S=V_{F} t=V_{F}\left(T-t_{R}\right)
$$

Where $t_{R}$ is the time when detonation wave arrived at $\mathrm{R}$ position. 


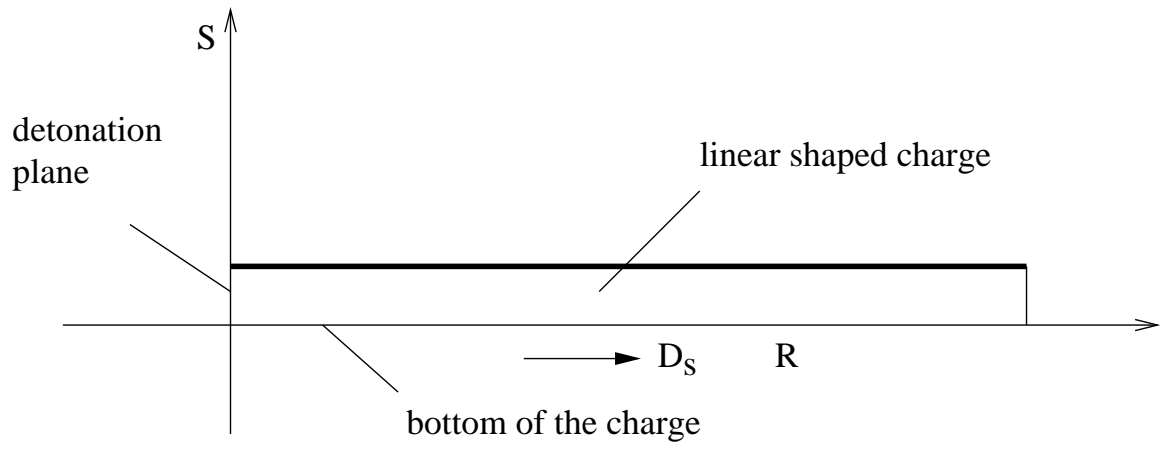

Fig. (8). The coordinate on the charge model.

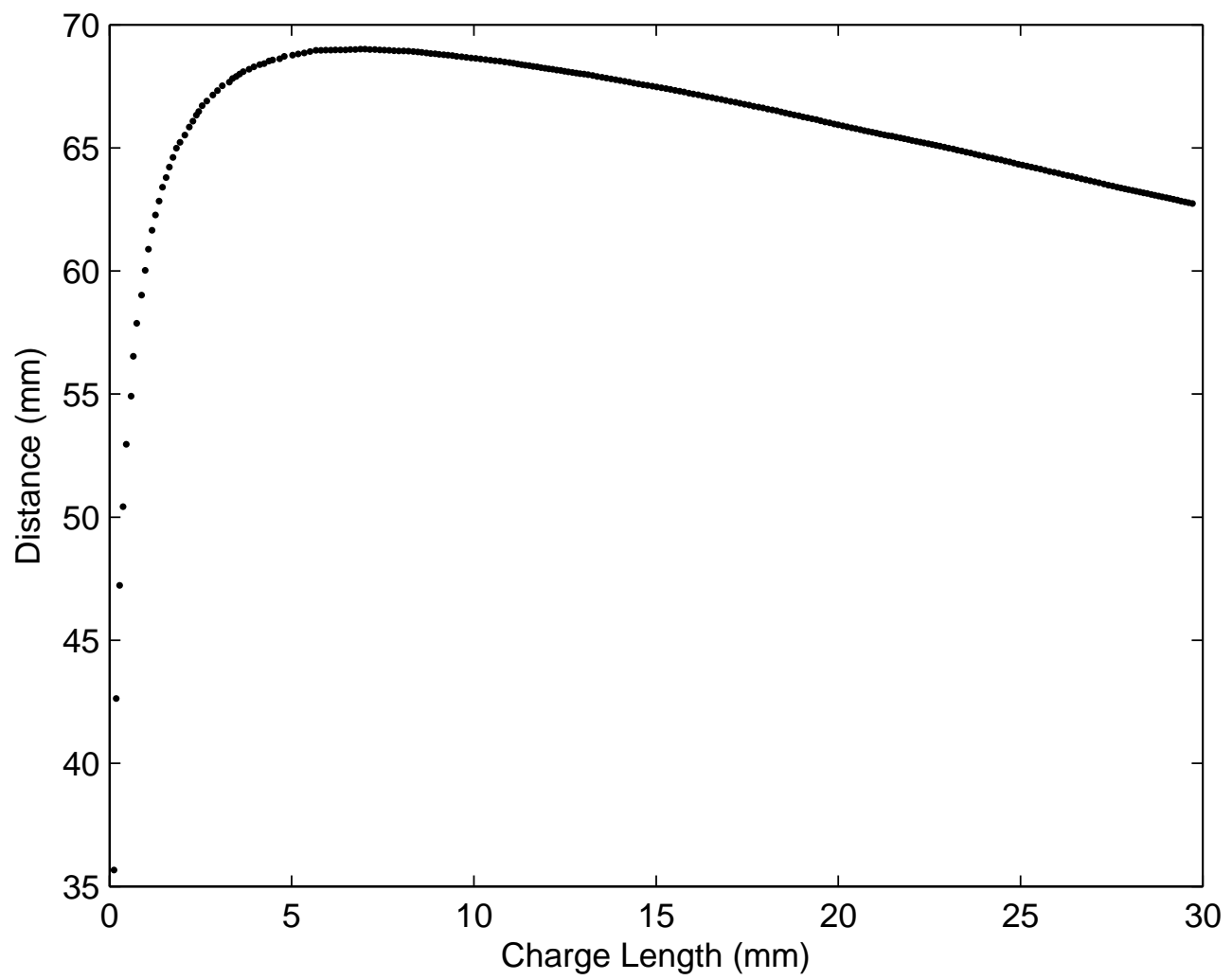

Fig. (9). The calculated shape of the penetrator tip.

$$
\begin{gathered}
R=\int_{0}^{t_{R}} D_{S} d t=D_{S} t_{R} \\
t_{R}=\frac{R}{D} \sqrt{1+\frac{2 \gamma L}{(1+\gamma) R}}
\end{gathered}
$$

With the parameters of real charge, the shape of LEFP tip is calculated and as shown in Fig. (9).

As can be seen from Fig. (9), the shape curve of LEFP was more bent near initiation point due to the velocity gradients. Bifurcate fracture showed up firstly in this part of LEFP as it continued to move. The shape curve of the last part was less bent.

Fig. (10) showed the position of the penetrator at time $t_{0}$ and $t_{1}$. The velocity of detonation end face $\mathrm{A}$ is $V^{A}$ and it can be decomposed to $V_{x}^{A}, V_{y}^{A}, V_{z}^{A}$. B is the lowest point of
LEFP and its velocity and corresponding velocity components are $V^{B}, V_{x}^{B}, V_{y}^{B}, V_{z}^{B}$ respectively. $\mathrm{AB}$ is stretched out on A $^{\prime} \mathrm{B}^{\prime}$ in LEFP movement. The main reason of the stretching is that there is velocity gradient in the direction of $\mathrm{y}$ and $\mathrm{z}$.

$$
\begin{gathered}
y_{A^{\prime}}=\int_{0}^{t_{1}} V_{y}^{A}(t) d t \\
y_{B^{\prime}}=\int_{0}^{t_{1}} V_{y}^{B}(t) d t+Y_{0}
\end{gathered}
$$

The elongation number of $\mathrm{A}^{\prime} \mathrm{B}^{\prime}$ in the direction of $\mathrm{y}$ :

$$
\Delta y=y_{B^{\prime}}-y_{A^{\prime}}-Y_{0}
$$

The horizontal distances from $\mathrm{A}^{\prime}, \mathrm{B}^{\prime}$ to o respectively are as follow:

$$
z_{A^{\prime}}=0
$$




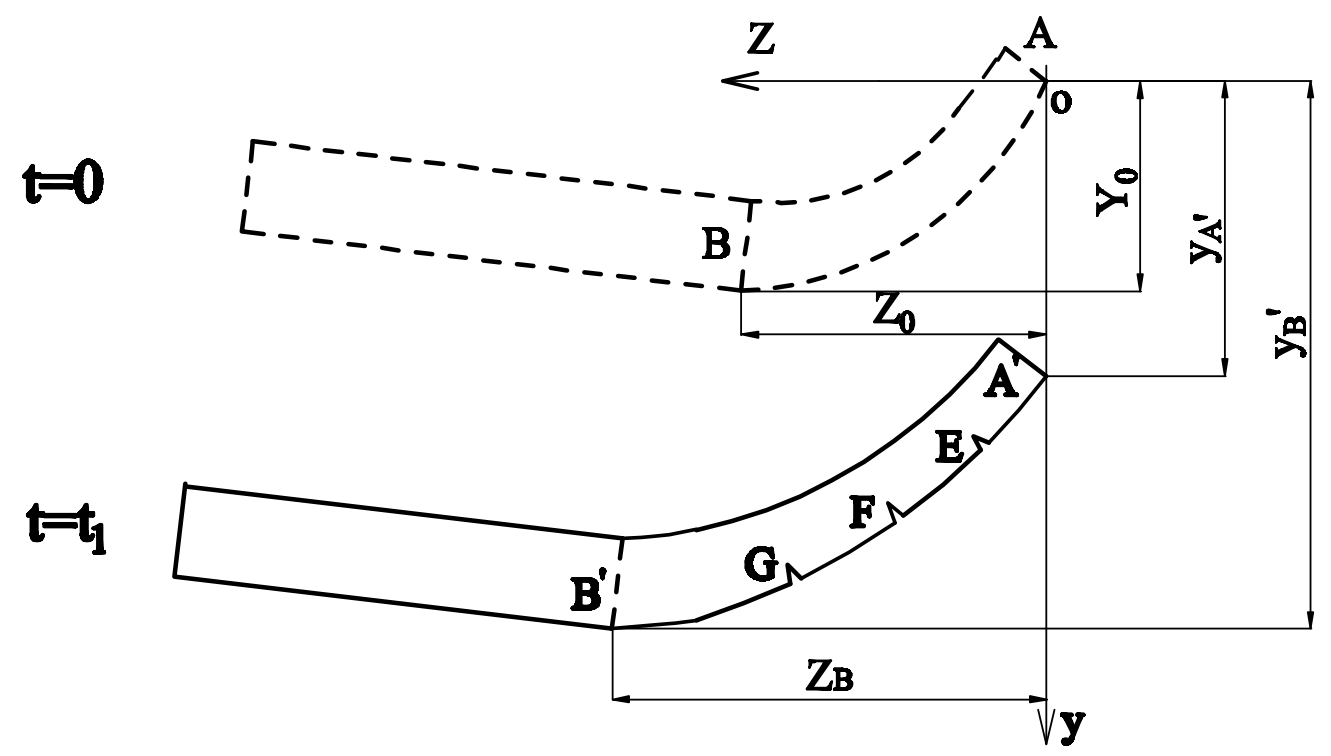

Fig. (10). The penetrator movement and extension process.

$$
z_{B^{\prime}}=\int_{0}^{t_{1}} V_{z}^{B}(t) d t+Z_{0}
$$

The extension in the direction of $z$ is:

$$
\Delta z=z_{B}-Z_{0}
$$

The total extension of $\mathrm{AB}$ is approximately

$$
\Delta l=\sqrt{(\Delta y)^{2}+(\Delta z)^{2}}
$$

And the elongation of $\mathrm{AB}$ is:

$$
\delta=\frac{\Delta l}{l_{0}}
$$

\section{Criterion of LEFP Bifurcate Fracture}

The oxygen-free copper crystal grain size of shaped charge liner has turned refiner under explosion loading and its tensile strength and fracture elongation are increased [5]. Assuming the maximum dynamic elongation is $\delta_{\max }$, if

$$
\delta \geq \delta_{\max }
$$

the bifurcate fracture will arise, which leads to the separating craters on the target.

\section{Analysis}

The AB segment is curve and the elongation percentage of LEFP head is bigger than that of LEFP tail, so the bifurcate fracture point of $\mathrm{AB}$ segment arises on the head of LEFP firstly. With the movement of LEFP, the bifurcate fracture points go up on the corresponding plane and the bifurcate fracture breach is bigger until the two parts separate completely.

In the process of LEFP stretching, the velocity of B point decreases with the deceasing of the adjacent element velocity. There is the velocity gradient in the course of LEFP due to the effect of velocity between every breach of LEFP, The longer the distance of LEFP movement in air is, the longer the stretching of LEFP will be, which leads to bifurcate fracture. Therefore the penetrating results are obtained in LEFP upon target experiment.

\section{CONCLUSIONS}

The results of theoretical analyze and numerical simulation agreed with that of experiment. On the discussions above, the following conclusions can be drawn:

1) Element velocities of the red copper penetrator were directly proportional to those of detonation wave. Near the detonation point, they increased when detonation grew up. The penetrator was bent when it has been formed, and there were velocity difference between sections.

2) The bent part would get more stretch effect on both $y$ and $z$ directions, and when the combined elongation was great than the dynamic elongation of red copper, the penetrator fractured.

3) The development of bifurcate fractures related to the distance which it traveled, and the more distance the penetrator traveled, the larger bifurcate fractures obtained.

4) Thus, as the stand-off was getting large, it caused separate craters on the target; as a result the cratering effect was weakened.

5) The way to eliminate bifurcate fractures is to decrease the velocity gradient in the penetrator, which can be approached by enlarge the initializing area.

\section{CONFLICT OF INTEREST}

None declared.

\section{ACKNOWLEDGEMENTS}

None declared. 


\section{REFERENCES}

[1] F. Rondot, Tracking the "Poorness" of a Linear Shaped Charge[C]. 23rd International Symposium on Ballistics Tarragona, Spain, vol. 16-20, p. 167, 2007.

[2] Y. Luo, S. Zhao-Wu and C. Xiao-Rong, Application Study on Blasting with Linear Cumulative Cutting Charge in Rock[J]. Chin. J. Energetic Mater., vol. 14, p. 236, 2006.
[3] L. Wei, F. Ning-Jun and Wang Zheng-Jie, Warhead Missile Fuze Analysis and Simulation[J]. J. Beijing Inst. Technol., vol. 17, p. 290, 2008.

[4] W.P. Walters, and J.A. Zukas, Fundamentals of Shaped Charge [M], John Wiley \& Sons, New York, 1989.

[5] Y. Zhuoyue, L. Baocheng and Z. Jiaping, The Formation Mechanism of Ultrafine Grain in Pure Iron Under Explosive Shock Loading[J]. Trans. Mater. Heat. Treat., vol. 22, p. 56, 2001.

Received: September 21, 2011

(C) Zhang and Gou; Licensee Bentham Open.

This is an open access article licensed under the terms of the Creative Commons Attribution Non-Commercial License (http://creativecommons.org/licenses/by$\mathrm{nc} / 3.0 /$ ), which permits unrestricted, non-commercial use, distribution and reproduction in any medium, provided the work is properly cited. 